\title{
Research on the Control Strategy of Photovoltaic Power Generation System Based on the Micro Grid
}

\author{
Hong Gang ${ }^{1}$, Peng Qiu ${ }^{2}$ and Yibo Zhang ${ }^{3}$ \\ Jinzhou Power Supply Branch, State Grid Liaoning Electric Power Supply Co. Ltd \\ Jinzhou, China \\ Email: Ganghong66@163.com ${ }^{1}$, qiupeng123@163.com ${ }^{2}$,zhangyibo@163.com ${ }^{3}$
}

\begin{abstract}
With the rapid growth of the electricity demand, UHVAC and UHVDC transmission and the distributed generation with the renewable energy become the key point of the development of power industry based on the goal of the harmonious development in the power industry at home. According to the certain topological structure, the micro grid is the network including the distributed power supply, energy storage power supply, and load-control devices. It is linked with the grid through the switch devices, realizing the effective management of the distributed generation. We can also find the value and benefits of the distributed generation for the power grid and the user. This paper discusses that the micro grid is the effective approach to solve the integration between distributed generation and power grid. It also summaries its concept and research status of the micro grid deeply. Then it knows the current application of photovoltaic power generation technology. Finally it concludes that the operation characteristic of the photovoltaic power generation system has the important research value in the micro grid.
\end{abstract}

Keywords: Control Strategy, Photovoltaic Power, power industry, application

\section{Introduction}

As national economy structure adjustment, in today's society the power supply quality, safety and reliability requirements is increasing day by day, and now the disadvantages of traditional large capacity power system exposed more prominent: Now the world's power supply system in large units, large power, high voltage as the main characteristics of single centralized power supply system, any fault caused by disturbance will cause great influence to the power grid, serious when can cause blackouts and even entire network collapse; Increased the load fluctuation of the market economy and power plant investment factors such as random variations, and large flexible power system will not be able to track the load variation, caused the hair transmission equipment investment capacity of waste; Centralized power grid structure of remote area power supply will cause the transmission cost is too high, and the centralized power supply system is difficult to realize the cogeneration, generating heat loss in vain. In addition, due to the energy constraints, the occurrence of such problems as environmental pollution, the greenhouse effect, and the embodiment of the distributed generation and energy saving, environmental protection and other advantages. Integrated the above several factors, developed countries have put more to the research on the developing electricity use clean renewable energy and distributed energy, distributed generation system is developing rapidly [1].

But LAN access to distributed generation system cost is high, not easy to control; the most important is it for power grid is not a controlled source, so big power grid system often adopts the method of limit, isolation to deal with distributed power, thus reducing its impact on power grid and the negative impact. In order to better play to the potential of 
distributed generation, and gradually formed a new form of organization - micro grid, effectively in the distributed power generation into the power grid system.

Photovoltaic power generation compared with other distributed energy, has irreplaceable advantages. However, the present study is more large photovoltaic power generation, independent photovoltaic power generation and the roof grid photovoltaic power generation technology, for many sets of small capacity of distributed power supply in parallel micro grid structure of the distributed power control strategy research is less. In addition, the present research in various micro power grid technology, for the convenience of analysis, often do simplify the processing of the dc side of the power, USES the constant current source or constant-voltage source instead of the actual power generation unit. Doing so largely affected as photovoltaic, wind power, and other forms of power generation are greatly influenced by the weather conditions, the power output of randomly distributed power supply in micro power grid work of the actual operating characteristics. Considering the above two factors, the control strategy of the micro power grid photovoltaic power generation systems research has important research value [2].

Photovoltaic power generation through the grid inverter is by detail. When the micro grid operation mode in the network, the voltage and frequency of the rigid support provided by power grid, photovoltaic power generation work in the state of voltage source or current source, using the traditional control strategy of photovoltaic power generation, adjust the power output, the system can sTable operation. When power grid failure occurs, the grid into the island operation mode, the voltage to the voltage amplitude and frequency should be the internal micro power controller is responsible for the adjustment. According to the different operating mode of micro power grid of micro source control requirements, is the traditional photovoltaic control mode is difficult to meet the requirements of flexible and table operation of micro power grid. So how to effective control of micro power grid photovoltaic power, different operating mode of the micro grid table operation and smooth switching between the pattern, is the key point of reliable operation of power grid. Above comprehensive analysis, based on the study on the control strategy for micro power grid photovoltaic power generation, first will adopt dc voltage source inverter dc side instead, applicable to the micro grid operation environment of the inverter control strategy was analyzed and then, in order to further get photovoltaic in micro power grid, the actual operation characteristics of the inverter dc side access photovoltaic cells on the photovoltaic power generation system in the actual operation characteristics are analyzed in the research of the grid.

Micro power grid is a distributed power supply, energy storage device, energy conversion device, load and related monitoring, protection device assembled small power distribution system. Micro power grid of small distributed power supply, power supply for more capacity which contains power electronic interface of small units, including the micro gas turbine, fuel cell, photovoltaic cells, small wind turbine and super capacitor, flywheel, battery energy storage device, etc. They pick up on the user side, has low cost, low voltage and low pollution, etc. The double pressure of environmental protection and energy depletion, forcing us to vigorously develop clean and renewable energy. Efficient distributed energy industry (cogeneration) space is huge development potential and interests. Improve power supply reliability and power quality requirement and long transmission constraints are driving near the load center set up the corresponding power supply. By micro electrical controller can realize the centralized control of the whole power grid, do not need to be distributed on the controller, and only USES conventional measuring devices, measurement device based on the rapid communication channel between local controllers. Distributed power supply and load on the controller was adopted to realize micro power grid transient control, micro grid centralized energy management system to achieve steady state security, economic operation analysis. 


\section{The Present Situation of Micro Grid}

\subsection{The Concept of Micro Power Grid}

A large number of distributed generations connected to the power system will be a large impact on the operation of the large power grid. In order to solve the problem of access between power grid and distributed generation, the micro grid structure arises at the historic moment. With big power grid access issues, micro power grid access standards for common connection point for micro power grid with large power grid, and not for micro grid inside each specific micro power supply, so the micro grid structure produces not only solve the problem of the large-scale access of distributed generation, give full play to the advantages of distributed generation, at the same time also brought a variety of other benefits for the user.

At present the definition of micro grid on international also each are not identical. Definition given by the American association of electrical reliability technology solutions for the micro grid is composed of load and micro power supply system, it can provide electricity and heat at the same time the inside of the micro grid power supply is mainly composed of power electronic devices in charge of energy conversion, and provide the necessary control micro grid relative to the external power grid characterized by single control unit, and can meet user requirements for power quality and power supply security [3]. Definition given by the project a micro power grid is the use of primary energy use micro power supply, can be divided into uncontrolled, some controllable and control all three kinds, and can be cold, heat, electricity regenerations equipped with energy storage device using power electronic device which can adjust the energy. The United States of Wisconsin, Madison, one is the concept of micro grid is given by a load and micro power of independent control system, to provide local electricity and heat.

\subsection{Micro Grid Research both at Home and Abroad}

As a new technology, micro power grid in the development of the countries presents different characteristics. Some developed countries in Europe and the micro grid research has made breakthrough progress. The United States put forward the concept of micro power grid in the year. Micro power grid project from the department of energy attaches great importance to, and in the heart of the development strategy of micro power grid as one of the three cornerstones of electric power system technology in the future. European based on its "smart grid" plan is put forward to make full use of distributed resources, intelligent technology, advanced power electronic technology, in order to realize the centralized power supply and distributed power generation efficiency. Micro power grid is regarded as the basic characteristics of the distributed network as well as the future European electricity network are an important part of a strategic research agenda. Japan is the world's micro grid research, its development mainly aim to the diversification of energy supply, reduce pollution, satisfy the user's individualized demand for electricity, Japanese scholars proposed flexible reliability and intelligent power supply system, its main idea is add some flexible ac transmission system devices in power distribution network, with its fast, flexible control to realize the optimization of energy structure of distribution network performance, satisfies the requirement of the user a variety of power quality. Besides the above countries, Canada, Australia and other countries also are carrying out a research into the micro grid work [4].

At present, the domestic focus on the distributed generation and distributed energy storage to carry out the related research, the study of micro power grid has just begun still no definite results. And micro power grid in meet the requirements of a variety of power quality and reliability of power supply has many advantages, it can completely as the existing power grid of a useful and necessary supplement. In short, the characteristics of 
micro power grid to adapt to the development of Chinese electric power demand and direction, so has a wide development prospect in our country.

\section{Control Strategy of Micro Power Grid Photovoltaic Power Generation System}

Photovoltaic power generation has broad application prospects and the micro power grid as a new way of grid-connected distributed on the structure and function is different from the traditional distributed generation system. Accordingly, the performance of the power electronic interface require for distributed power change [5]. The traditional control strategy of photovoltaic power generation is not applicable for the table operation of the micro grid, so you need to research new suiTable for micro power grid operation control strategy of photovoltaic power generation system. The photovoltaic power generation system consists of two levels of study in this topology, the first will adopt dc voltage source inverter dc side instead, to simplify the system structure, applicable to the micro grid operation environment of the inverter, this paper analyzes the control strategy then inverter dc side by photovoltaic cells, thereby to actual operation characteristics of photovoltaic power generation system in micro grid made a further analysis and research.

\subsection{The Work Principle and Characteristics of Photovoltaic Cells}

The solar cell is a kind of using photovoltaic effect converts solar energy into electrical energy device. Normally, semiconductor materials for photovoltaic cell is a kind of special material between the conductor and an insulator, and any material atoms, the semiconductor atoms is also by the positively charged nucleus and negatively charged electrons, the outer layer of the semiconductor silicon atoms have a electronic, fixed track turning around the nucleus. When the role of external energy, the electrons is will off track and become free electrons, and in the position of the original left behind a "hole", in the pure silicon crystal, the number of free electrons and holes is equal. If in silicon crystals doped with boron, mortar and other elements, as a result of these elements can capture electron, it became a hole type semiconductor, usually with a symbol if adding to release the electronic elements such as phosphorus, arsenic, it became a electronic semiconductor, with symbols. If combine these two kinds of semiconductor, interface to form a knot. The secrets of the photovoltaic cells are on the "knot", "like a wall, hindering the movement of electrons and holes. Solar cells are of a similar principle and diode can be explained in simple knot. When the sun to the junction, within the semiconductor due to the light energy to release electrons, atoms and accordingly the electronic - whole pair, is produced as a result, the junction between the electromotive force, known as the voltage. This phenomenon is what is said above "photovoltaic effect". When connected to the load, the external circuit there is an electric current passes through, so the formation of battery components one by one, put them in series, in parallel, can produce certain voltage and current, and power output.

A characteristic of the solar cell contains the most technical features, is the most important aspects of system analysis. A characteristic of solar cell is to point to in a certain sunshine intensity and temperature, the relationship between the output current and voltage of solar battery, as shown in Figure 1. Characteristic curve shows that solar cell is neither constant voltage source, nor a constant current source, it shall not provide any big power for load, is a kind of nonlinear dc power supply. Output current is relatively constant in most of the work voltage scope, finally after more than one voltage, current quickly fell to zero. 


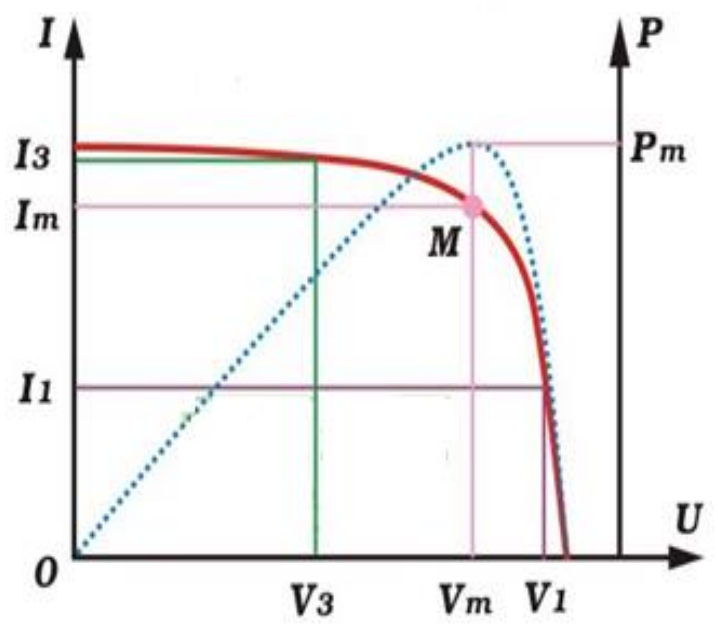

Figure 1. The Relationship Between the Output Current and Voltage of Solar Battery

\subsection{Control Strategy of Traditional Photovoltaic Power Generation}

(A) Traditional photovoltaic inverter control strategy does not apply to the micro grid operation

Photovoltaic inverter control mode can be classified into voltage source voltage control, voltage source current control and current source voltage source current control and current control of four methods. Current source inverter, the dc side is connected with a large inductance is used to provide a table dc input, but large inductance often lead to system dynamic response is poor, so most of the current world grid inverter adopts is given priority to with voltage source inverter. According to the output voltage type inverter control can be divided into voltage control and current control.

Access the power distribution system can be treated as infinite capacity ac voltage source. If the output of the photovoltaic grid inverter adopts voltage control, is actually a voltage source and voltage source parallel operation system, this kind of circumstance to ensure the system table running, you must adopt phase-locked control technology to realize synchronous with power grid, on the basis of table operation, can be adjusted by the size of the inverter output voltage and the phase shift to control the output active and reactive power output of the system. But as a result of phase lock loop response is slow, the inverter output voltage value difficult to precise control, circulation problems, such as may occur if you don't take special measures, generally the same power level voltage source parallel operation mode is not easy to obtain excellent performance. If the output of the inverter with current control, the need to control the inverter output current to track power grid voltage, can achieve the goal of parallel operation. Due to its control method is relatively simple, so the more widely used. But this kind of targeted output power grid converter control method can work in micro grid network mode, does not apply to the micro grid work in island mode. Isolated cases, the need of network of distributed power supply can provide reference can provide a table frequency and voltage of power quality [6].

In addition, for photovoltaic power generation system, also need to consider in a special response under fault condition, namely the islanding prevention and countermeasures. So-called island effect refers to the power supply when the electric power company, because of the failure accident or power failure maintenance when tripping, each client's solar energy grid generation system failed to detect the state of power outages and cut itself off the mains network, formed by the solar energy grid 
generation system and the load around the formation of an electric power company can't grasp the self power island. Island effect may be on the distribution of the whole system equipment and user equipment adverse impact. So you must prevent the occurrence of islanding, the general measures is to stop the operation of photovoltaic power generation. But doing so will not be able to ensure that sensitive load of uninterrupted power supply, reduce the reliability of the system, from the economic point of view, photovoltaic power shutdown, and can not the largest use of energy.

Therefore, the traditional photovoltaic inverter control strategy applies only to the micro grid network operating mode, and does not apply to the micro grid island operation mode and the transition of two kinds of micro power grid operation mode, so the whole system, the control strategy cannot meet the micro power grid safe and reliable operation, need to study a new suiTable for micro power grid operation of the photovoltaic inverter control strategy.

(B) Traditional photovoltaic power output control strategy does not apply to the micro grid operation

Traditional photovoltaic power generation has always been a maximum power point tracking control; ensure the maximum power output of photovoltaic battery. But when photovoltaic is applicant to micro power grid, the power output pattern will be different. Because micro power grid connected with island two kinds of operation mode, the networking mode, network capacity can be treated as infinitely great, at this point in the micro grid photovoltaic power same as the traditional grid control purpose, only need to ensure the maximum power output can be in an island mode, due to the limited capacity, micro power grid to ensure energy supply and demand balance in the system is the premise of normal operation of micro grid, therefore, at this time of the micro grid photovoltaic power supply can't only according to the output power of maximum power point.

\section{The Control Strategy of Existing Micro Power Grid Photovoltaic Inverter}

From the system point of view, the micro grid power supply, the load, energy storage device and control device, such as the formation of a single controlled source, to the user at the same time supply of electricity and heat. Distributed power of micro grid is called micro power supply, hereinafter referred to as the source. Micro grid can connect with power grid operation; can also be used in the power grid with large power grid failure or need to run off island.

When micro power system networking, inverter power source are connected to the power grid through the feeder, structurally similar to ordinary, at this time the capacity of the power grid can be regarded as infinite, in power grid voltage and frequency for reference, according to the scheduling instruction timely adjust the power output, micro power grid in terms of external power grid is a controllable power unit, improve traditional to impact and influence of the power system. After the large power grid failure, micro power grid into the island operation mode, distributed power loss of power grid voltage and frequency, for each inverter unit needs to adjust the power output according to their own capacity, reasonable distribution of load, automatic adjust and maintain the stability of the output voltage amplitude, frequency, and to ensure that each inverter unit is consistent with the output voltage waveform.

According to the characteristics of micro power grid, distributed in the micro grid power put forward the corresponding control requirements. It's mainly embodied in the following aspects:

(a) Any of the distributed power supply system should not access or resection.

(b) To choose its own operating point.

(c) The active and reactive power independent control of distributed power supply. 
(d) In addition to the network and the islands of the operation mode of two kinds of table, there is also the transformation between the two modes transition process. It is worth noting that the mode conversion is not restart the inverter, but to make inverter to realize seamless switching operation, in order to ensure the normal operation of the network sensitivity load.

(e) To allow different capacity of inverter power supply in parallel, can realize the inverter power source apportionment load.

Through the analysis on characteristics of micro power grid operation, flexible micro power grid operation mode power supply with high quality services, without the perfect control system. Because many micro sources in the micro grid number, it is difficult to through a centralized controller rapid response and the corresponding control of the whole system, once a component failure in the system or software error, can lead to paralysis of the whole system, so the micro grid control should be based on local information only to control the energy storage device and distributed power supply, making autonomic response to events in the grid, rather than the traditional way by the unified dispatching of power grid.

\subsection{According to the Type of Power Inverter adopts different Control Strategies}

In actual micro grid, different types of distributed power control features may vary greatly, such as micro gas turbines and fuel cells for power supply, control is easier to implement, can according to the given active power and reactive power control, and can be easily implemented heart empty, and the latter can be used to ensure micro power grid frequency and voltage stability in power source such as wind power and photovoltaic power generation, the power output are greatly influenced by the weather, the size of the intermittent power has obvious, to ensure a constant power output, it requires a large capacity of energy storage device, so it is not the economy, the power supply control objectives should be how to guarantee the maximum utilization of renewable energy, general control strategy is used for this purpose [7].

For distributed power supply and load in micro grid has the characteristics of dispersion, according to the different types of distributed power supply adopts different control mode. For fuel cells, miniature gas turbine power series method, based on droop for photovoltaic cells, wind power, the power supply adopts the current decoupled control method, ensure the well the reliable operation of the two kinds of micro grid work mode.

When the micro grid pattern transformative, due to the distributed constant power control strategy, is conducive to the stability of the system, can better realize smooth transition between models. But it also exists deficiency on the one hand, the island in micro grid mode, because of the distributed power supply work to run, run so far is difficult to achieve the balance of power system, managers need to have energy auxiliary control power, on the other hand, when the micro grid operation of the island, provided by the control of the distributed power system voltage and frequency, so only when the control of the power supply capacity compared with the control power supply capacity is large enough, the robust stability of the system could provide reference voltage frequency, otherwise it will affect the table operation of the system [8].

\subsection{The Multi-loop Feedback Control Strategy of Distributed Power Inverter}

Micro network distributed power inverter in multi-loop feedback control strategy. Main circuit structure for single phase full bridge inverter circuit, the inverter output voltage after filter output [9]. After detection signal to filter the output voltage and filtering inductance current, is obtained by power controller, through the voltage current double loop controller are given the mating signal finally by the drive circuit to control the operation of the inverter. 
When the micro grid pattern transformative, due to the control strategy is the same, it can better realize smooth transition between models. But it also exist deficiencies due to the two kinds of micro power grid operation mode adopts power controller based on droop, makes the distributed power supply such as photovoltaic cells and wind power are greatly influenced by external factors of the power supply when the networking mode, cannot in accordance with the current can achieve maximum power output power, is actually caused the waste of resources, can be seen from the simulation results also, networking mode of the inverter output active power output of the active power is less than the island mode, namely the inverter in networking mode does not reach the maximum power output.

\subsection{Based on the thought of Virtual Synchronous Generator Inverter Control Strategy}

Algorithm module using electromechanical transient mathematical model of synchronous generator, effective simulation of synchronous generator stator and rotor mechanical properties of electrical characteristics of power controller hereinafter referred to as controller and voltage frequency controller is referred to as "controller respectively according to the power dispatching command power and FM surge two functions, pre synchronization unit ensure that satisfies grid conditions after closing contactor, mode select signal is used to select control module, control module or synchronous control module [10].

Synchronous generators as the main power equipment of large-scale power system, its unique properties make it has obvious advantages in grid-connected power generation. The designed synchronous generator output characteristics of inverter power supply, and connecting with the inverter power supply itself fast response characteristics used in the micro grid, is helpful to solve the inverter technology problem of grid voltage, power regulation, to make the micro grid research can draw lessons from the grid control technology, is good for the development of the micro grid. Existing shortcomings of this method is when the inverter power switch to control the load when the power is independent, is restricted by the inverter power supply network running status, if the control is not reasonable, in the mode switch will have greater frequency fluctuations and voltage fluctuation and damage to equipment.

\section{Conclusion}

In order to solve the problems of the distributed energy access to power grid, the micro grid concept is put forward and used for many years. China's current development of micro power grid and the development of distributed energy resources (renewable energy) synchronization carry on, despite its technology research and application of heats up, but the technical foundation is weak, the industrialization operation will take time. Especially the lack of national policies and regulations guide but also become the primary bottleneck in the development of micro power grid. The development of China's micro grid technology will also be a long and tortuous process. Happily, in recent years, the country is a new policy to actively encourage the development of new energy and new energy distribution network access convenient. Especially in the remote mountains, island and other places, the development of the micro grid solve many practical problems, but also greatly improve the quality of life of local residents. Believe that China's micro grid technology will be on the path of rapid development. 


\title{
6. Acknowledgements
}

The authors gratefully acknowledged the financial support from Liaoning Education Department (serial number: L2013494), Nature Science \& Foundation of Liaoning Province (serial number: 2013020124) and National Natural Science Foundation of China (serial number: 61372195, 61371200).

\section{References}

[1] R. H. LASSETER. Microgrids and distributed generation. Journal of Energy Engineering, 27, 11 (2007)

[2] L. Shu and J. H. Zhang. Study on some key problems and technique related to micro grid. Power System Protection and Control, 38, 19 (2014)

[3] C. S. Wang and Z. Wu. Research on key technologies of microgrid. Transactions of China Electro technical Society, 29, 2 (2014)

[4] Q. Yang and S. J. Ma. Design of microgrid operation model and control. Transactions of China Electrotechnical Society, 30, 26 (2011)

[5] J. H. Zhang and B. Zeng. Key issues and research prospects of active distribution network planning. Automation of Electric Power Systems, 27, 24 (2013)

[6] B. Li and J. S. Dong. Study on the control mode for islanded micro system network. Power System and Clean Energy, 2, 30 (2014)

[7] W. H. Lu. Comparative study of the earthing systems for micro-grid. Power System Protection and Control, 35,19 (2012)

[8] L. Han. Application of Photovoltaic Technology in Energy Saving Building. Low Voltage Electrical Apparatus, 2, 4 (2009)

[9] H. M. Liu and C. Y. Huang. The micro grid vulnerability assessment based on the theory of the risk. Electric power system and its automation, vol. 29, 23 (2009)

[10] B. Li and Z. Q. Bo. Design and research on protection and control of smart distribution grid. Proceedings of the CSEE, 3, 20 (2009)

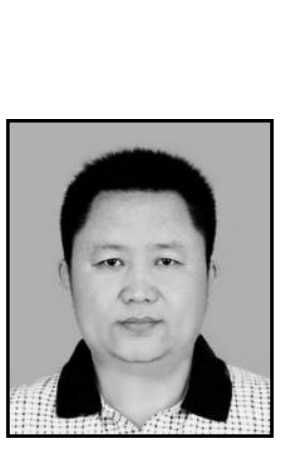

\begin{abstract}
Authors
Hong Gang, He received the B.E. degree from Northeast Dianli University, China in 1993. He is currently working in Jinzhou Power Supply Branch, State Grid Liaoning Electric Power Supply Co. Ltd.
\end{abstract}

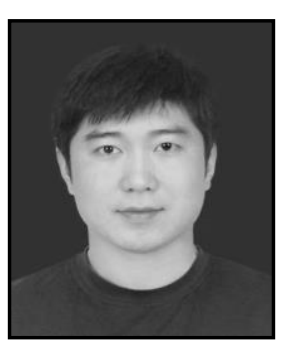

Peng Qiu, He received the B.E. degree from Shenyang Institute of Engineering, Liaoning, and China in 2004. He is currently working in Jinzhou Power Supply Branch, State Grid Liaoning Electric Power Supply Co. Ltd.

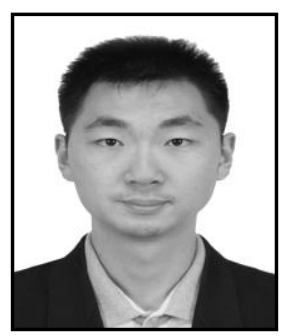

Yibo Zhang, He received the B.E. degree from Shenyang Institute of Engineering, Liaoning, and China in 2012. He is currently working in Jinzhou Power Supply Branch, State Grid Liaoning Electric Power Supply Co. Ltd. 
International Journal of Grid and Distributed Computing

Vol. 9, No. 8 (2016) 